\title{
Potential Osteoporosis Recovery by Deep Sea Water through Bone Regeneration in SAMP8 Mice
}

\author{
Hen-Yu Liu, ${ }^{1,2}$ Ming-Che Liu, ${ }^{3,4}$ Ming-Fu Wang, ${ }^{5}$ Wei-Hong Chen, ${ }^{1,2}$ Ching-Yu Tsai, ${ }^{1,2}$ \\ Kuan-Hsien Wu, ${ }^{1,2}$ Che-Tong Lin, ${ }^{6}$ Ying-Hua Shieh, ${ }^{7}$ Rong Zeng, ${ }^{8}$ and Win-Ping Deng ${ }^{1,2,9,10}$ \\ ${ }^{1}$ Stem Cell Research Center, Taipei Medical University, Taipei, Taiwan \\ ${ }^{2}$ Graduate Institute of Biomedical Materials and Tissue Engineering, Taipei Medical University, Taipei, Taiwan \\ ${ }^{3}$ School of Dentistry, College of Oral Medicine, Taipei Medical University, Taipei, Taiwan \\ ${ }^{4}$ Department of Urology, Taipei Medical University Hospital, Taipei, Taiwan \\ ${ }^{5}$ Department of Food and Nutrition, Providence University, Taichung, Taiwan \\ ${ }^{6}$ Graduate Institute of Oral Rehabilitation Sciences, Taipei Medical University, Taipei, Taiwan \\ ${ }^{7}$ Department of Family Medicine, Taipei Medical University, Wan Fang Hospital, Taipei, Taiwan \\ ${ }^{8}$ Department of Orthopedic Surgery, The Affiliated Hospital, Guangdong Medical College, Zhanjiang 524001, China \\ ${ }^{9}$ Translational Research Laboratory, Cancer Center, Taipei Medical University, Taipei, Taiwan \\ ${ }^{10}$ Cancer Center, Taipei Medical University Hospital, Taipei, Taiwan
}

Correspondence should be addressed to Rong Zeng; 13802825311@139.com and Win-Ping Deng; wpdeng@ms41.hinet.net

Received 3 January 2013; Revised 22 June 2013; Accepted 27 June 2013

Academic Editor: Wei-Chiang Lin

Copyright (c) 2013 Hen-Yu Liu et al. This is an open access article distributed under the Creative Commons Attribution License, which permits unrestricted use, distribution, and reproduction in any medium, provided the original work is properly cited.

\begin{abstract}
The aim of this study is to examine the therapeutic potential of deep sea water (DSW) on osteoporosis. Previously, we have established the ovariectomized senescence-accelerated mice (OVX-SAMP8) and demonstrated strong recovery of osteoporosis by stem cell and platelet-rich plasma (PRP). Deep sea water at hardness (HD) 1000 showed significant increase in proliferation of osteoblastic cell (MC3T3) by MTT assay. For in vivo animal study, bone mineral density (BMD) was strongly enhanced followed by the significantly increased trabecular numbers through micro-CT examination after a 4-month deep sea water treatment, and biochemistry analysis showed that serum alkaline phosphatase (ALP) activity was decreased. For stage-specific osteogenesis, bone marrow-derived stromal cells (BMSCs) were harvested and examined. Deep sea water-treated BMSCs showed stronger osteogenic differentiation such as BMP2, RUNX2, OPN, and OCN, and enhanced colony forming abilities, compared to the control group. Interestingly, most untreated OVX-SAMP8 mice died around 10 months; however, approximately 57\% of DSW-treated groups lived up to 16.6 months, a life expectancy similar to the previously reported life expectancy for SAMR1 24 months. The results demonstrated the regenerative potentials of deep sea water on osteogenesis, showing that deep sea water could potentially be applied in osteoporosis therapy as a complementary and alternative medicine (CAM).
\end{abstract}

\section{Introduction}

Osteoporosis, a common disease caused by imbalanced bone remodeling, is a global public health problem. Patients with osteoporosis are often accompanied with pain, disability, and decline in the quality of life, rise in mortality, and depletion of local health care budget [1-4]. The major type of osteoporosis occurred in postmenopausal women with an age range of 50-70 [5]. Bone density index rapidly decreased after the menopause, due to sex hormone imbalance and the lack of estrogen. The imbalance of homeostasis between osteoclasts and osteoblasts also leads to increased bone resorption [6,7]. In addition, senile osteoporosis with increased age and the reduction of growth hormone $(\mathrm{GH})$ which stimulates renalsynthesized 1 alpha,25-dihydroxyvitamin D3 (1,25(OH)2D3) is also another cause of osteoporosis $[8,9]$. Age-related bone loss causes bone trabecular thinning as well as the loss of cortical layer of bone tissue, and the cortex becomes porous which will increase the femoral neck fracture rate [10]. For osteoporosis, supplemental dietary calcium and vitamin D may reduce the risk of fractures in postmenopausal women [11]. Drugs, lifestyle changes, home safety, and hip protection 
are viable approaches for the prevention of osteoporosis. According to the World Health Organization Criteria (WHO) statistics, the penetration rate of osteoporosis in women over the age of 65 is up to $35 \%$; hence, the advanced treatment for osteoporosis has become emergent.

Deep sea water (DSW) generally refers to sea water from a depth of more than 200 meters (m). It could be characterized by its purity, abundant nutrients, and minerals. Currently, DSW has been applied in the ground of food, agriculture, cosmetic, and medical field due to its high contents of unique minerals including sodium $(\mathrm{Na})$, magnesium $(\mathrm{Mg})$, calcium $(\mathrm{Ca})$, potassium $(\mathrm{K})$, zinc $(\mathrm{Zn})$, and vanadium $(\mathrm{V})$ [12]. DSW has been reported to stimulate both osteoblastogenesis and osteoclastogenesis in bone turnover [13]. $\mathrm{NaCl}$ from DSW also improves the biochemical properties of bone. DSW combined with soluble silicon as natural material could promote cell proliferation of osteoblast and enhance the osteogenesis-related gene expression in animal studies [13]. The DSW utilized in this study is drawn from the Pacific Ocean at a depth of $662 \mathrm{~m}$ and a distance of 5 kilometers $(\mathrm{km})$ off the coast of Hualien County, Taiwan [14, 15], which contains abundant amounts of trace elements, including high concentrations of four essential minerals: $\mathrm{Mg}(96200 \mathrm{mg} / \mathrm{L})$, $\mathrm{K}(10800 \mathrm{mg} / \mathrm{L}), \mathrm{Na}(9010 \mathrm{mg} / \mathrm{L})$, and Ca $(39 \mathrm{mg} / \mathrm{L})$.

Our previous study has demonstrated that transplantation of platelet-rich plasma- (PRP-) treated NIH3T3-G cells into OVX-SAMP8 mice significantly reversed osteoporosis. We also showed that PRP could not only increase bone regeneration but also reduce bone marrow adiposity in the osteoporotic mice [16-18]. In this study, we investigated the possibility of the treatment of osteoporosis by DSW. For osteoporotic model, SAMP8 mice received bilateral salpingooophorectomy at 4 months old and subsequently fed with DSW for 15 days. The effects of DSW on bone regeneration were then analyzed by bone mineral density, micro-CT, bone structure with HE stain, and the activities of isolated bone marrow stromal cells. Here, we demonstrated that DSW not only induced bone regeneration but also strongly recovered bone loss in OVX-SAMP8 mice. In addition, we have observed that DSW would be effective in prevention of osteoporosis and might be a complementary and alternative medicine (CAM).

\section{Materials and Methods}

2.1. Characterization of Deep Sea Water (DSW). DSW was obtained from the Pacific Ocean at a depth of $662 \mathrm{~m}$ $[14,15]$. The obtained DSW was subjected to filtration to remove microorganism and virus and then concentrated. The elements contained in concentrated DSW were measured by inductively coupled plasma mass spectroscopy. As shown in Supplemental Table 1, the concentrated DSW contained high amounts of several essential minerals such as magnesium $(\mathrm{Mg})$, potassium $(\mathrm{K})$, sodium $(\mathrm{Na})$, and calcium (Ca) (see Supplementary Material availbale online at http://dx.doi.org/10.1155/2013/161976). The final hardness of concentrated DSW was determined as $400,000 \mathrm{mg} / \mathrm{L}$ by using calcium and magnesium concentrations.
2.2. Cell Line and Cell Viability. Mouse preosteoblast cell line (MC3T3-E1, ATCC CRL-2593) was provided by Dr. Alexander T.H Wu (Taipei medical University, Taipei, Taiwan) and was cultured in 96 well plates $\left(1 \times 10^{4}\right.$ cells/well $)$ in alpha minimum essential medium ( $\alpha$-MEM) supplemented with $10 \%$ fetal bovine serum (FBS) or/and different concentration of DSW (ranged from 500 to $2000 \mathrm{HD}$ ). MTT reagent was added into each well on day 3 of cell growth in culture, and cell viability was detected by Multiskan PC (Thermo Lab). For the cell counting assay, MC3T3 $\left(1 \times 10^{4}\right)$ were seeded in $6 \mathrm{~cm}$ dish containing DSW-derived medium (hardness of $1000 \mathrm{mg} / \mathrm{L}$ )and incubated at $37^{\circ} \mathrm{C}$ in $5 \% \mathrm{CO}_{2}$ atmosphere. After $72 \mathrm{hrs}$, MC3T3 were collected, and the cell numbers were counted by trypsin and ethylenediaminetetraacetic acid treatment.

2.3. Experimental Animals. All the animal experiment protocol was approved by the Institutional Animal Care and Use Committee of Taipei medical University. SAMP8 mice were ovariectomized (OVX) at 4 months of age to induce osteoporosis and then used in this experiments. Mice were grouped into the following (six mice per group): control group (CTRL, receiving PBS) and DSW group (receiving DSW). Both mice were suggested for daily water uptake which is based on a $22 \mathrm{~g}$ mouse consuming $5.2 \mathrm{~mL}$ water per day.

2.4. Serum ALP, Mg, and Ca Analyses. All mice were sacrificed and the extracted blood specimens were obtained at 4 months. The plasma concentrations for ALP, Mg, and $\mathrm{Ca}$ were then determined by a photometric method according to the manufacturer's instructions (Fuji Dri-Chem Clinical Chemistry Analyzer FDC 3500).

2.5. Bone Mineral Density and Micro-CT Analysis. Dualenergy X-ray absorptiometry (DEXA) analysis was used for the measurement of bone mass in the spine, left/right knee, and left/right femurs. BMD (XR-36; Norland Corp; host software revision 2.5.3, scanner software revision 2.0.0) was performed 4 months after DSW treatment. All mice were sacrificed and their femurs and tibia bones were collected at 4 months for detecting the trabecular bone and bone volume by micro-CT (Skyscan-1076, Skyscan, Belgium). For trabecular bone analysis and 3D imaging, construction was operated at $50 \mathrm{KV}, 200 \mathrm{uA}, 0.4^{\circ}$ of rotation step, $0.5 \mathrm{~mm}$ AI filter, and $9 \mu \mathrm{m} /$ pixel of scan resolution. Each group contains 6 animals.

2.6. Histological Analysis. For histological determination, bone sample was fixed in 10\% formalin and decalcified in 14\% EDTA for 3 days. Bone sections $(10 \mu \mathrm{m})$ were subjected to paraffin-embedding and then stained with hematoxylin and eosin $(\mathrm{H} \& \mathrm{E})$ staining to detect the trabecular bone in the bone tissue.

2.7. Isolation of Bone Marrow Cells. Bone marrow stromal cells (BMSCs) were harvested from femurs and tibias of 


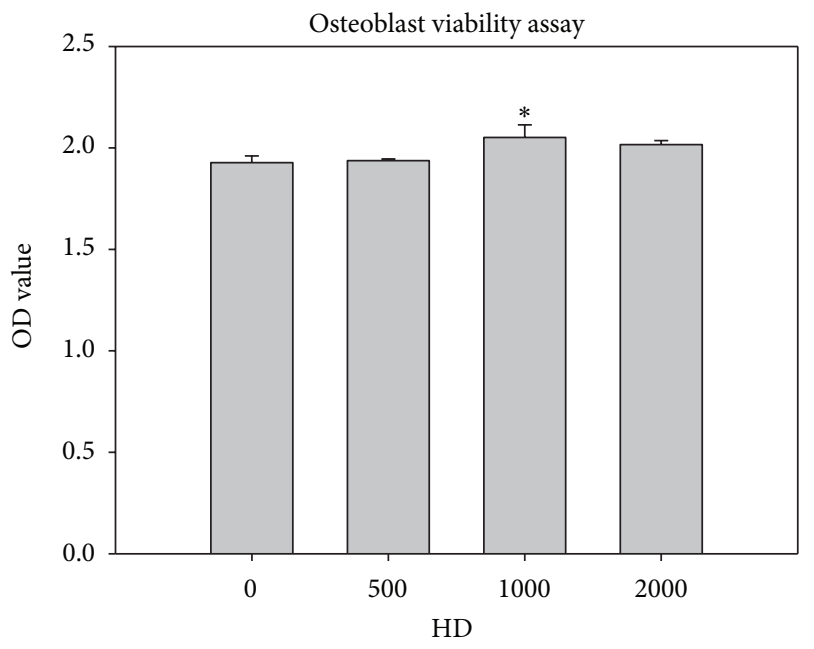

(a)

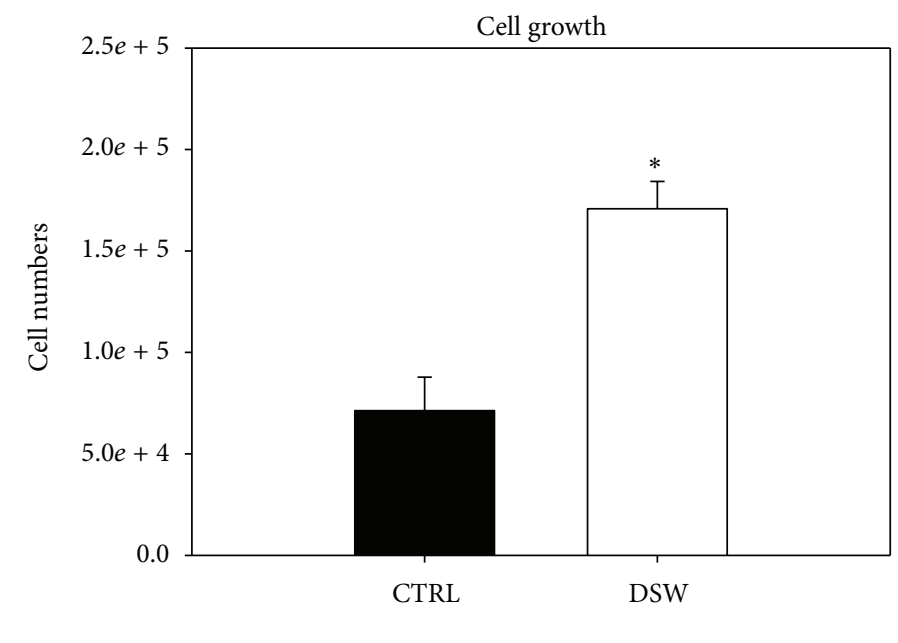

(b)

FIGURE 1: Optimization of hardness of DSW by cell viability of preosteoblast. Comparative proliferation profiles of preosteoblast (MC3T3) in DSW-enriched medium were analyzed by MTT assay (optical densities, mean 6 SD for 3 separate replicates). The MC3T3 cells treated with DSW of hardness (HD) 1000 showed the highest cell viability; $t$-test, ${ }^{*} P<0.05$.

DSW-treated mice and vehicle-treated mice (CTRL) after 4 months treatment. BMSCs were washed out in the bone marrow and centrifuged at $1000 \mathrm{rpm}$ for $5 \mathrm{~min}$. Cells were all cultured in $\alpha$-MEM supplemented with $10 \%$ FBS for one week to remove the nonadherent cells and then washed with PBS. The adherent cells, indicated the BMSCs, were collected for ethylenediaminetetraacetic acid treatment.

2.8. Cell Proliferation and Colony-Forming Unit of BMSCs In Vivo. BMSCs were cultured in $\alpha$-MEM supplemented with $10 \% \mathrm{FBS}$ and/or DSW treatment for 3 days, and the cell numbers were counted for evaluating their proliferation. For colony formation assay, BMSCs were cultured in maintenance medium after 14 days and then fixed with $4 \%$ formaldehyde. Fixed cells were then stained with $0.5 \%$ crystal violet in methanol for $10 \mathrm{~min}$, and formed colonies were then counted.

2.9. RT-PCR Analysis. Total RNA from BMSCs was extracted using TRIzol regent (Invitrogen Life Technologies). Gene expression levels were measured by RT-PCR. Primer sequences were indicated as follows: bone morphogenetic protein (BMP2): forward primer $5^{\prime}$-GGTCCTTGCACCAAGATGAAC- $3^{\prime}$; reverse primer $5^{\prime}$-CAACCCTCCACAACCATGTC- $3^{\prime}$, and temperature $62^{\circ} \mathrm{C}$; osteopontin $(\mathrm{OPN})$ : forward primer $5^{\prime}$-ATGAGATTGGCAGTGATT-3', reverse primer $5^{\prime}$-GTTGACCTCAGAAGATGA-3', and temperature $48.8^{\circ} \mathrm{C}$; osteocalcin $(\mathrm{OCN})$ : forward primer $5^{\prime}-\mathrm{CAG}-$ CTTGGTGCACACCTAAGC- $3^{\prime}$, reverse primer $5^{\prime}$-AGGGTTAAGCTCACACTGCTCC- $3^{\prime}$, and temperature $55^{\circ} \mathrm{C}$; runt-related transcription factor 2 (RUNX2): forward primer $5^{\prime}$-ACTTTCTCCAGGAAGACTGC- $3^{\prime}$; reverse primer $5^{\prime}$ GCTGTTGTTGCTGTTGCTGT- $3^{\prime}$, and temperature $55^{\circ} \mathrm{C}$; glyceraldehyde 3-phosphate dehydrogenase (GAPDH): was used as an internal control (CTRL) forward primer $5^{\prime}$ GCTCTCCAGAACATCATCCCTGCC-3'; reverse primer
5'-CGTTGTCATACCAGGAAATGAGCTT-3', and temperature, $55^{\circ} \mathrm{C}$. PCR products were separated by electrophoresis on $1 \%$ agarose gels (Agarose I; AMRESCO) and visualized with ethidium bromide staining.

2.10. Statistical Analysis. All results were represented as mean \pm standard deviation (SD). Significant differences between the two groups were determined by Student's $t$-test, $P$ value $<$ 0.05 .

\section{Results}

3.1. Effect of Deep Sea Water (DSW) Hardness on the Cell Growth of Preosteoblast. To determine the effects of different hardness of DSW water on the cell viability of preosteoblasts, MC3T3 cells were cultured in DSW-derived medium for $48 \mathrm{hrs}$ and analyzed by MTT assay. As shown in Figure 1(a), the DSW with hardness of 50 and $2000 \mathrm{mg} / \mathrm{L}$ did not affect the cell viability of preosteoblasts, yet DSW with hardness of $1000 \mathrm{mg} / \mathrm{L}$ slightly increased the cell viability of MC3T3 cells. Hence, we further evaluated the cell growth effects of DSW with hardness of $1000 \mathrm{mg} / \mathrm{L}$ on MC3T3 cells by using cell-counting assay. After $72 \mathrm{hrs}$ of culture, MC3T3 cells showed 2- to 3-fold enhanced cell growth in DSW-derived medium (hardness of $1000 \mathrm{mg} / \mathrm{L}$ ) compared to the control medium (Figure 1(b)). These results indicated that $1000 \mathrm{mg} / \mathrm{L}$ displays the optimal hardness of DSW for the cell growth of preosteoblasts. Therefore, we utilized DSW with hardness of $1000 \mathrm{mg} / \mathrm{L}$ in the following experiments.

3.2. Effect of DSW on Serum Alkaline Phosphatase (ALP), Calcium (Ca), and Magnesium (Mg) Activity in OVX-SAMP8 Mice. Based on the in vitro results, DSW of hardness 1000 was applied to OVX-SAMP8 mice for 4 months. We first evaluated the in vivo osteogenic effects of DSW by using 


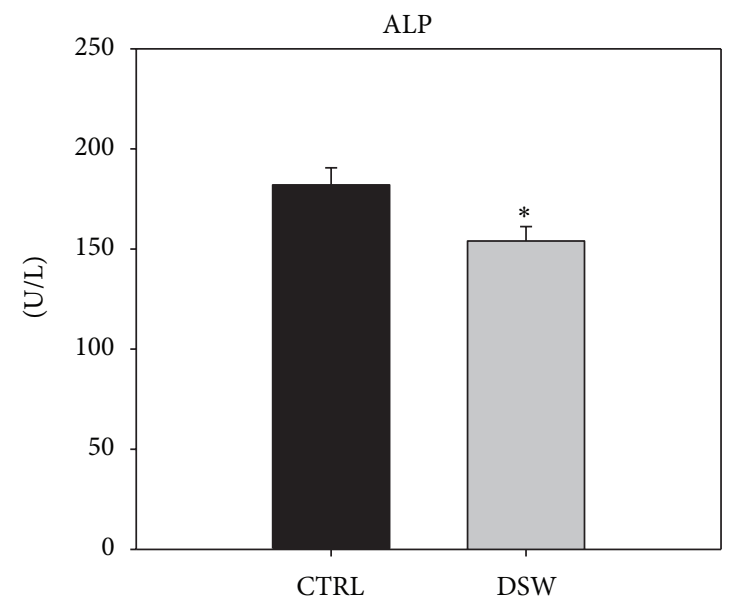

(a)

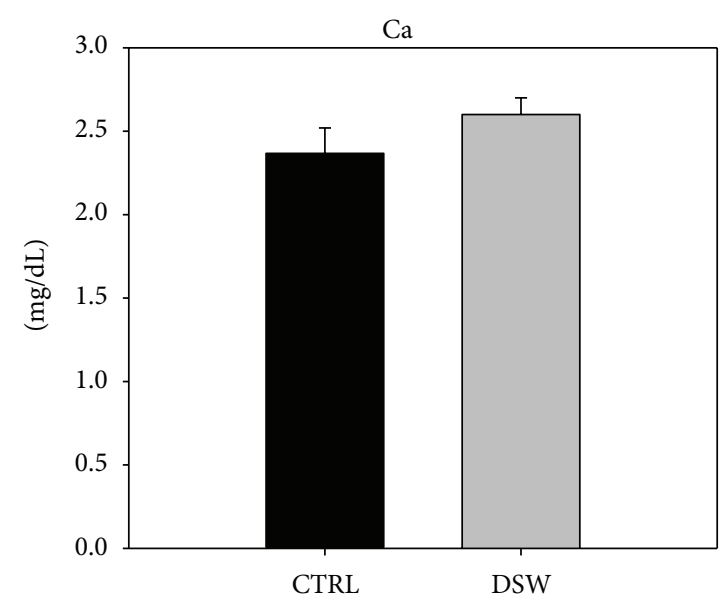

(b)

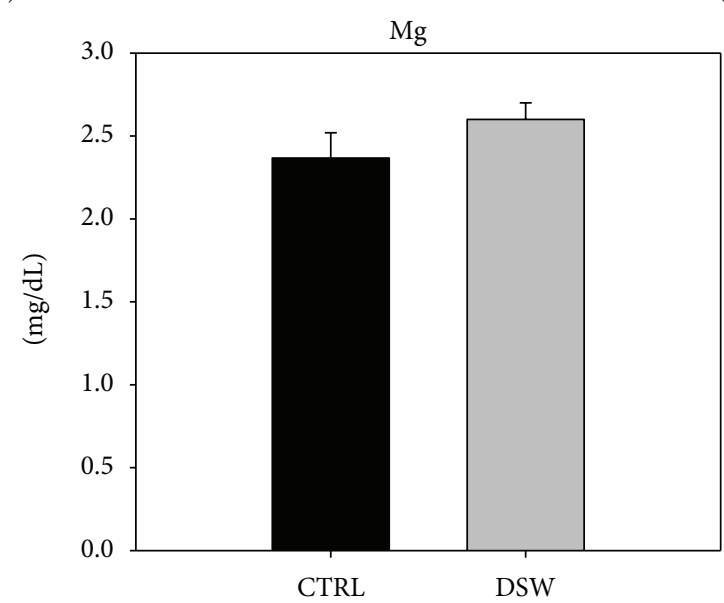

(c)

FIGURE 2: The effect of DSW treatment on serum ALP, Ca, and Mg activity. The serum ALP, Ca and Mg levels after 4 months DSW treatment was measured by ELISA assay. Serum ALP levels presented a significant decrease in DSW-treated mice (a). In contract, Ca and Mg showed no significant different in DSW group compared with control mice ((b) and (c)). Each bar represents the average from six animals; $t$-test, ${ }^{*} P<0.05$ versus CTRL group.

serum levels of ALP, Ca, and Mg. Serum ALP values reflect the increased turnover associated with bone destruction of aging, menopause, and various conditions affecting bone metabolism. Increased serum ALP levels are associated with an increased risk of rapid bone loss in peri- and postmenopausal women [19-21]. Ca and Mg play important roles in bone homeostasis and metabolism. Decreased serum levels of $\mathrm{Ca}$ and $\mathrm{Mg}$ have been shown to contribute to the risk of osteoporosis [22-24]. After 4 months DSW treatment, significantly lower ALP activity was evident in the DSW group as compared to control group (Figure 2(a)), which means that DSW could recover the bone loss in OVX-SAMP8 mice. Meanwhile, no significant difference was found in $\mathrm{Ca}$ and $\mathrm{Mg}$ levels between the DSW and control group (Figures 2(b) and 2(c)).

3.3. Quantitative Analysis of BMD in DSW-Treated Mice. DSW was used for prevention of OVX-SAMP8 osteoporotic mice, and bone density scores of spine, knee (right/left), and femurs (right/left) were determined by dual-energy X-ray absorptiometry (general scheme, Figure 3(a)). As demonstrated in Figure 3, 4 months after treatment, DSW of hardness 1000 significantly improved BMD of OVX-SAMP8 mice, compared with vehicle-treated OVX-SAMP8 mice, indicating that DSW induced bone regeneration and recovered bone mass loss in these osteoporotic mice (Figure 3(b)).

3.4. Photomicrographs for Bone Recovery in OVX-SAMP8 Mice by DSW. The improvement in BMD scores in DSWtreated animals was further supported by bone morphological analysis. Both micro-CT 2D and 3D imaging demonstrated higher trabecular area and volume in DSW-treated OVX-SAMP8 animals (left and middle two columns, resp., Figure 4(a)). Meanwhile, histological sections of bone tissues from DSW-treated mice also showed more trabecular bone areas in the bone marrow (right two columns, Figure 4(a)). After the relative trabecular bone volume ratio to the total bone volume (BV/TV) was measured, it was clear that a higher percent bone volume ratio (upper panel, Figure 4(b)) and trabecular bone number (lower panel, Figure 4(b)) were also found in DSW-treated OVX-SAMP8 mice. 

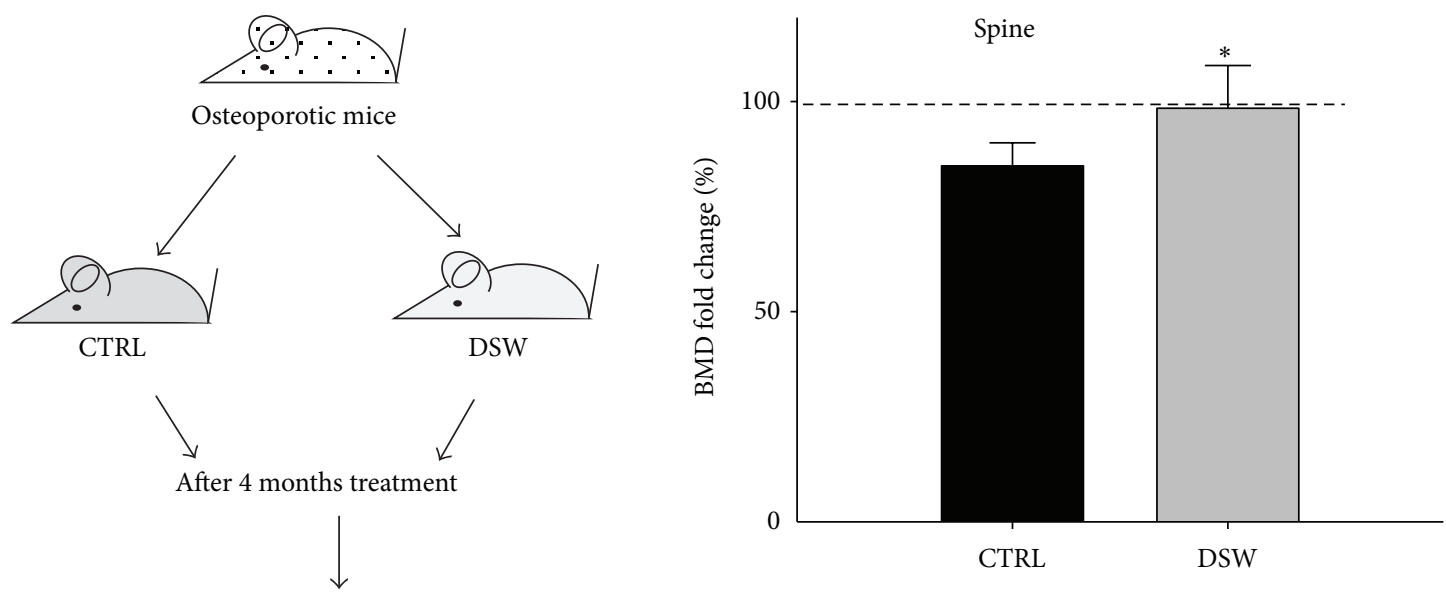

To determine bone mineral density
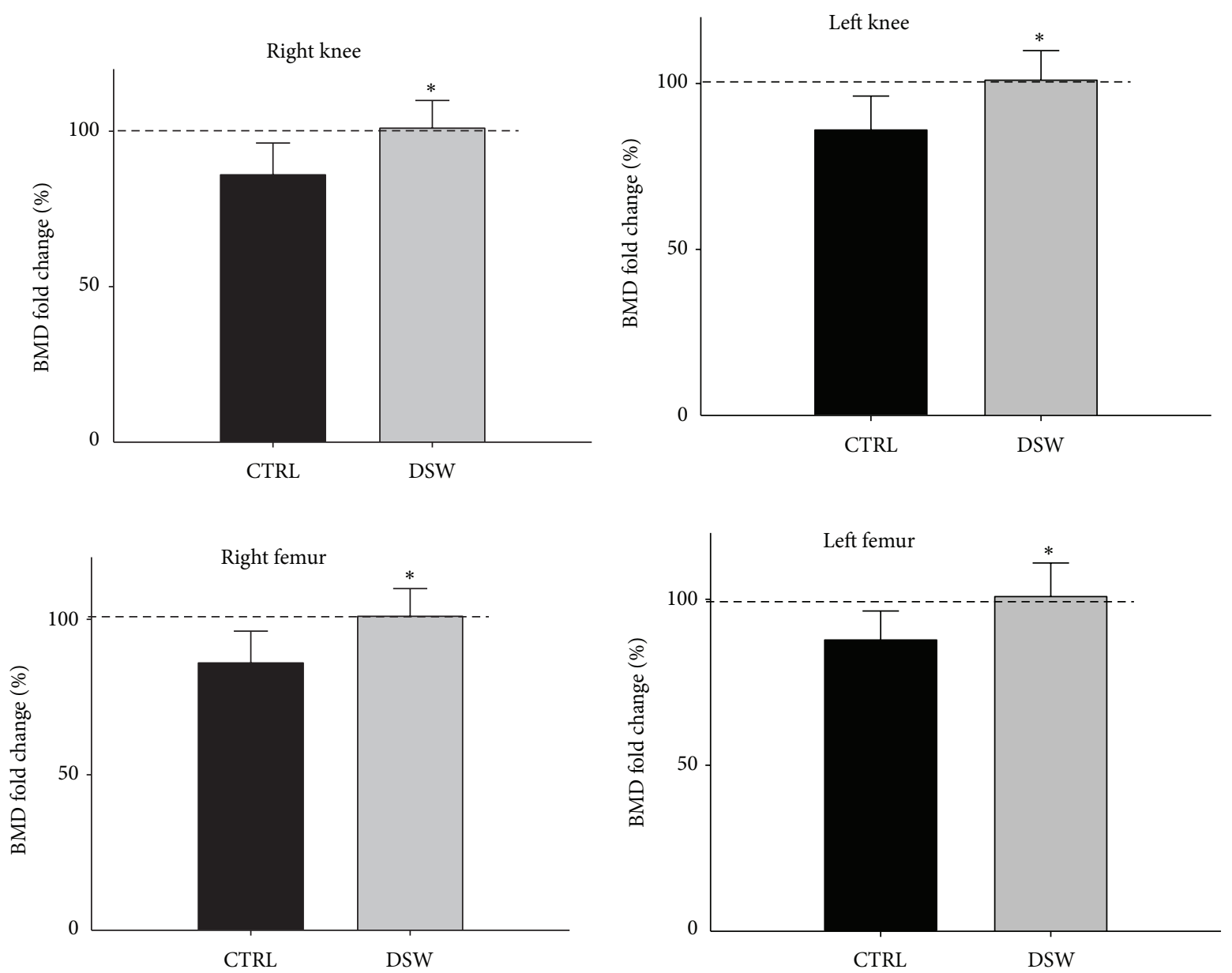

(a)

(b)

FIGURE 3: Quantitative analysis of BMD in DSW-treated and control mice. Bone density scores (BMD) of spine, knee (right/left), and femurs (right/left) were measured by Dual-energy X-ray absorptiometry after 4 months treatment (a). DSW-induced bone formation and decreased bone loss were observed in the DSW-treated OVX-SAMP8 mice (b). Values (means + SD) indicate relative BMD levels normalized to month 0 BMD (before operation $=100 \%$; dashed line), respectively; ${ }^{*} P<0.05$ determined by $t$-tests; $n=6$ of each group. 

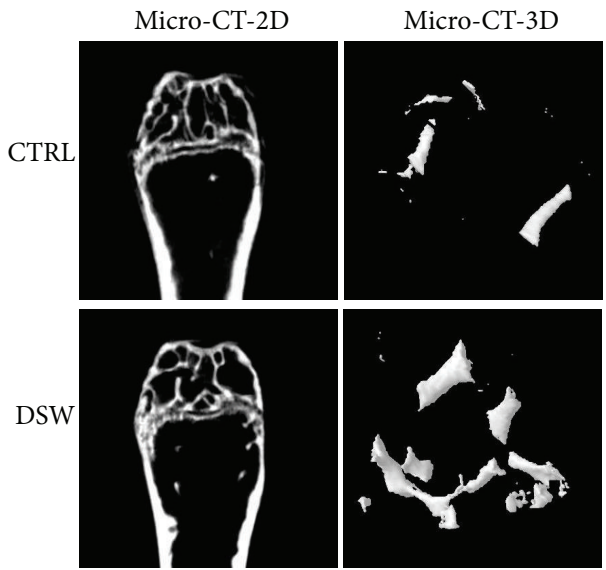

(a)
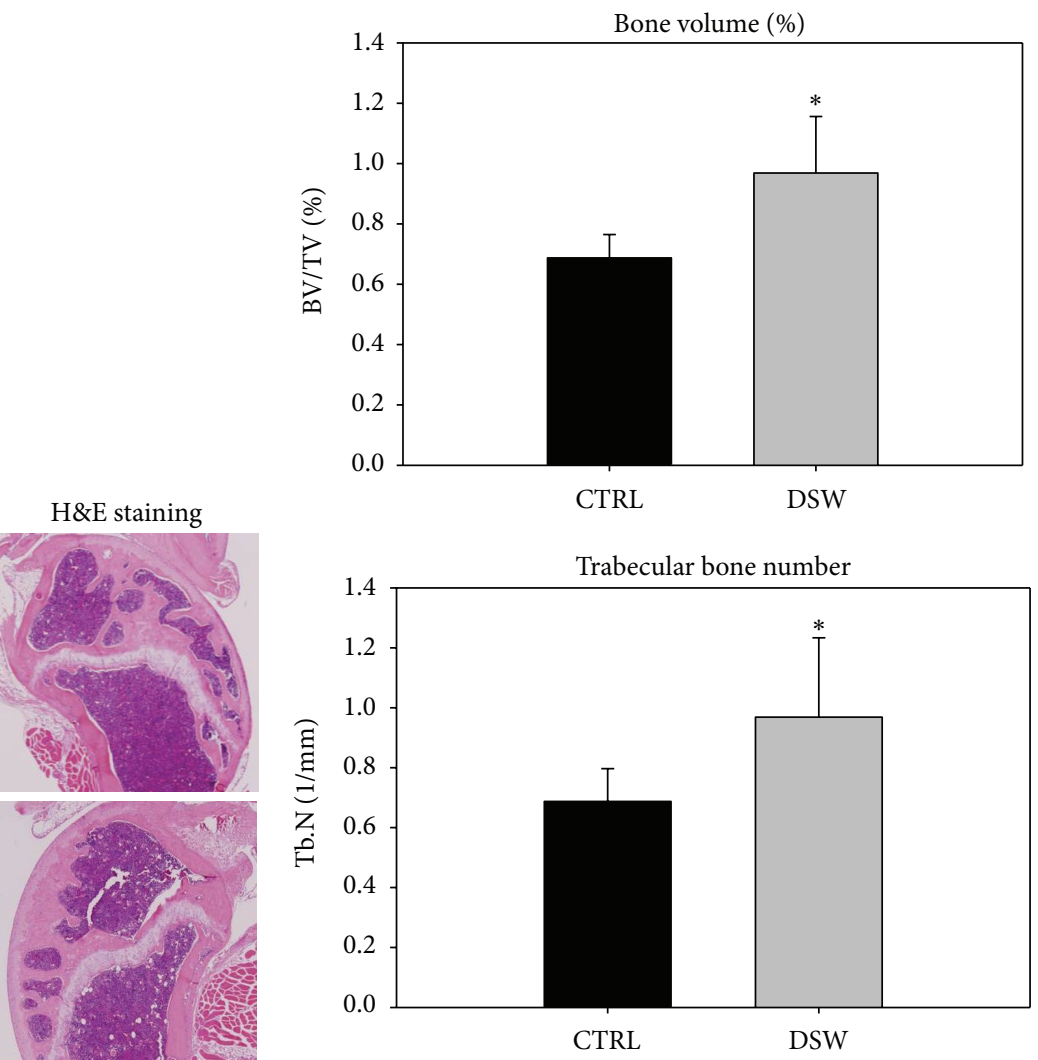

(b)

FIGURE 4: Effects of DSW on bone structure of OVX-SAMP8 mice. Comparative analyses of bone structure between control and DSWtreated OVX-SAMP8 mice. Micro-CT imaging observed that bone structure (trabecular/cortical bone, 2D), trabecular bone volume (3D), and trabecular bone mass were increased in the DSW-treated OVX-SAMP8 mice after 4 months treatment. H\&E staining represented a higher ratio of bone mass in DSW-treated mice (a). The volume of trabecular bone (bone volume/total bone volume (BV/TV)), and the numbers of trabecular bone (Tb.N) were calculated (right panel), and bars represented the average from six animals (b); $t$-test, ${ }^{*} P<0.05$ versus CTRL group.

3.5. The Proliferation and Colony-Forming Ability of Bone Marrow Stem Cell (BMSC) Derived from DSW-Treated Mice. To validate these observations and determine the effect of DSW on bone microenvironment in OVX-SAMP8 mice, BMSCs in DSW-treated mice were isolated and examined for cell proliferation and colony-forming ability (general scheme, Figure 5(a)). The BMSCs from DSW-treated SAMP8 mice demonstrated significantly higher proliferative activity and higher numbers of colonies as compared to those from vehicle-treated mice after 7 days incubation (Figures 5(b) and 5(c)). This finding suggested that the BMSCs from DSWtreated SAMP8 mice had statistically significant proliferative and colony-forming abilities.

3.6. Effects of DSW on Osteogenic Differentiation of BMSCs In Vivo. Following the characterization scheme in Figure 5, osteogenic differentiation markers, including BMP2 (regulate the transcription factor Runx2 expression), RUNX2 (an early stage marker for osteogenesis), OPN (an intermediate marker for osteogenesis), and OCN (a late stage marker for osteogenesis) mRNA transcripts of BMSCs from DSW-treated OVX-SAMP8, were examined and compared. The mRNA level of RUNX2, BMP2, OPN, and OCN was significantly upregulated in DSW-treated mice when compare to control mice (Figure 6(a)). Moreover, the Alizarin Red S staining showed an increased level of matrix mineralization in the BMSCs isolated from the DSW-treated group, as compared to the control group (Figure 6(b)).

3.7. Survival of Osteoporotic Mice Treated with DSW. In addition to significantly improving bone trabecular architecture and BMD, the DSW could extend the life span of OVXSAMP8 mice, which was markedly longer than that of the untreated OVX-SAMP8 (Figure 7). Most untreated OVXSAMP8 mice died around 10 months; however, approximately $57 \%$ of DSW-treated groups lived up to 16.6 months, a life expectancy similar to the previously reported life expectancy for SAMR1 24 months [16].

\section{Discussion}

Previously, we have demonstrated the osteogenic regeneration mechanism by stem cells and platelet-rich plasma in OVX-SAMP8 mice [16]. In this study, we extended to 


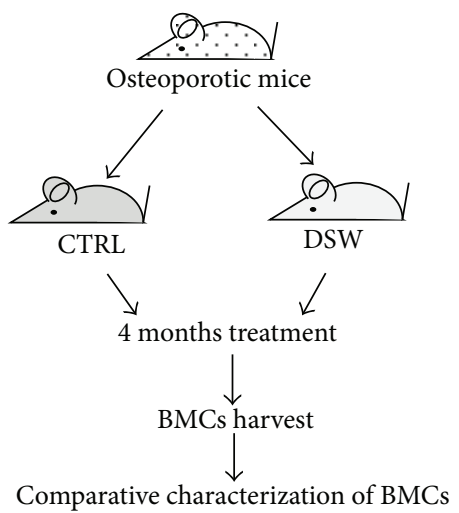

(a)

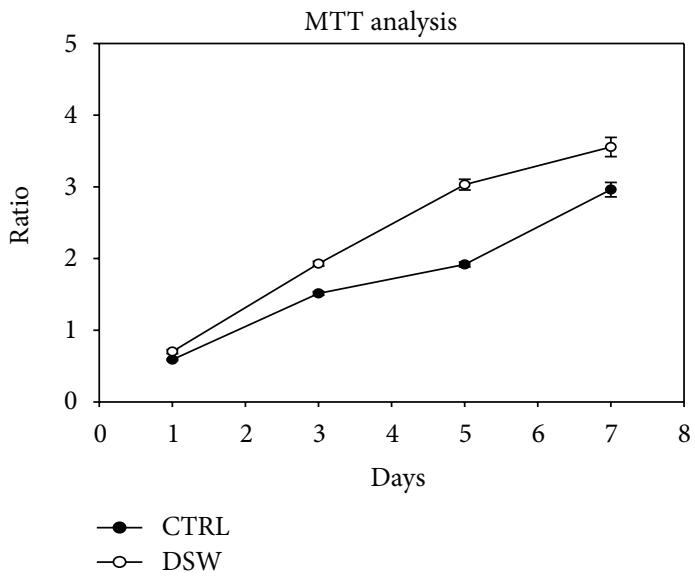

(b)
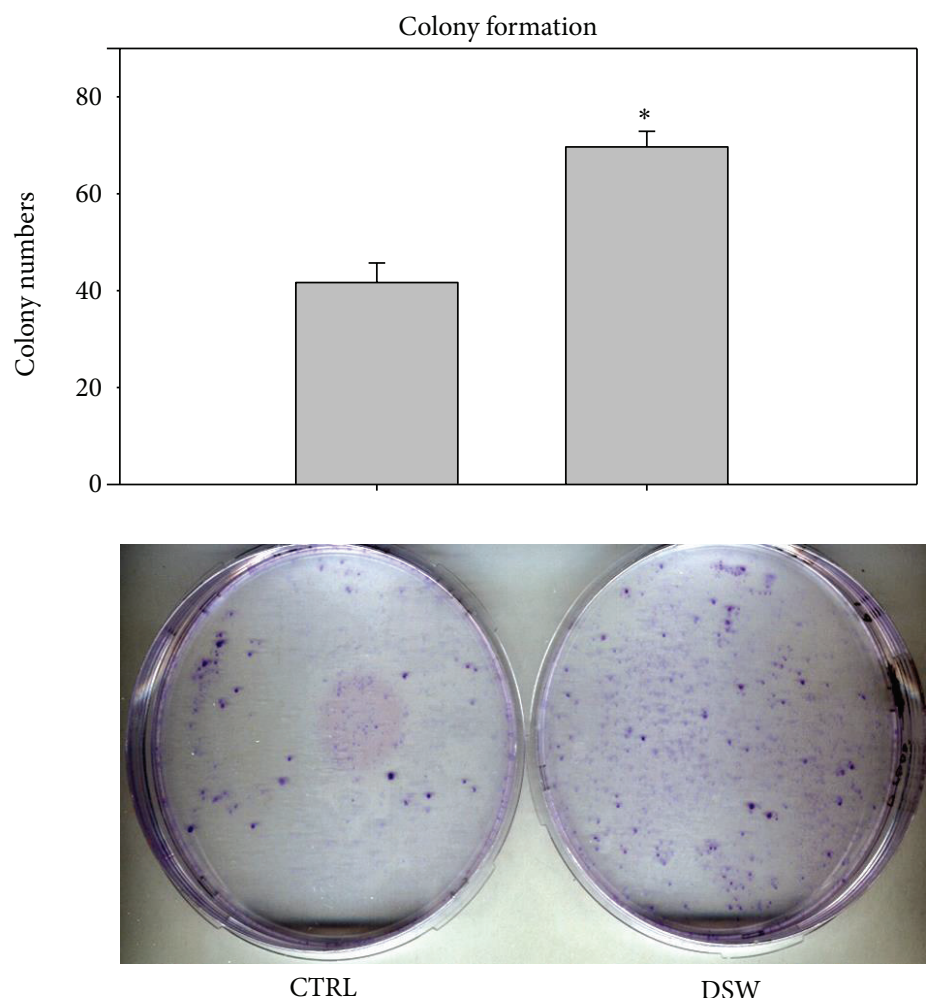

(c)

FIGURE 5: Ex vivo proliferation and colony-forming ability of isolated BMSCs. Comparative proliferation profiles of BMSCs from DSW and vehicle-treated mice were demonstrated by MTT assay ((a) and (b)). BMSCs were cultured for 14 days, and their colony forming abilities were assayed. Data was expressed quantitatively in the upper panel (c). Representative results of 3 experiments are demonstrated; $t$-test, ${ }^{*} P<0.05$ versus CTRL group.

examine the feasibility of using deep sea water (DSW) as a molecular cocktail to modulate the osteogenesis in osteoporotic mouse model. DSW contained major trace elements such as magnesium $(\mathrm{Mg})$ and calcium $(\mathrm{Ca})$, that have been reported to regulate bone metabolism. $\mathrm{Mg}$ and $\mathrm{Ca}$ were also found to induce murine osteoblast differentiation in MC3T3 cells. When MC3T3 cells were cultured in Mg- and Ca-free medium, their osteoblast differentiation marker osteocalcin (OCN) was reduced [25]. Epidemiologic studies showed a good correlation between $\mathrm{Mg} / \mathrm{Ca}$ and bone density, in which low $\mathrm{Mg}$ and $\mathrm{Ca}$ intake might decrease bone mass [26, 27], bone turnover, and also cause high risk of fracture and osteoporosis. Moreover, the hardness (HD) of DSW which resulted from the composition of $\mathrm{Mg}$ and $\mathrm{Ca}$ also reported to modulate osteogenesis $[28,29]$. In this study, our result showed that DSW of hardness $1000(1000 \mathrm{HD})$ appeared to be the optimal condition for osteoblast proliferation (Figure 1) and was applied for later experiments.

Serum alkaline phosphatase (ALP) is a group of enzymes found primarily in bone tissue. The primary importance of measuring ALP is to check the possibility of bone disease such as fractures and bone loss $[30,31]$. The decreased serum ALP activity and bone mass recovery were found in early postmenopausal woman with osteoporosis after hormone replacement therapy [32]. From the biochemical analysis, OVX-SAMP8 mice exhibited decreased ALP activity after 4 months DSW treatment (Figure 2). The decreased ALP activities were evidenced by bone mineral density (BMD) which indicated that bone quality in OVX-SAMP8 mice was enhanced by DSW (Figure 3). Interestingly, there was no significant difference in $\mathrm{Ca}$ and $\mathrm{Mg}$ levels after DSW treatment compared to control group. In the present study, OVXSAMP8 mice exhibited increased BMD and decreased bone loss after 4 months treatment with DSW. The histological and micro-CT 2D and 3D imaging data also demonstrated that $\mathrm{BV} / \mathrm{TV}$ ratio, trabecular bone numbers, and volume were strongly enhanced in DSW-treated OVX-SAMP8 animals (Figure 4). BMD has been shown to be an important factor to determine the strength of cancellous bone and trabecular bone $[33,34]$. In addition to BMD, trabecular structural parameters, such as fractal dimension or tissue volume, could enhance the prediction of bone mechanical quality $[35,36]$. These analyses indicated that DSW treatment reduced the bone loss and induced the bone recovery. 

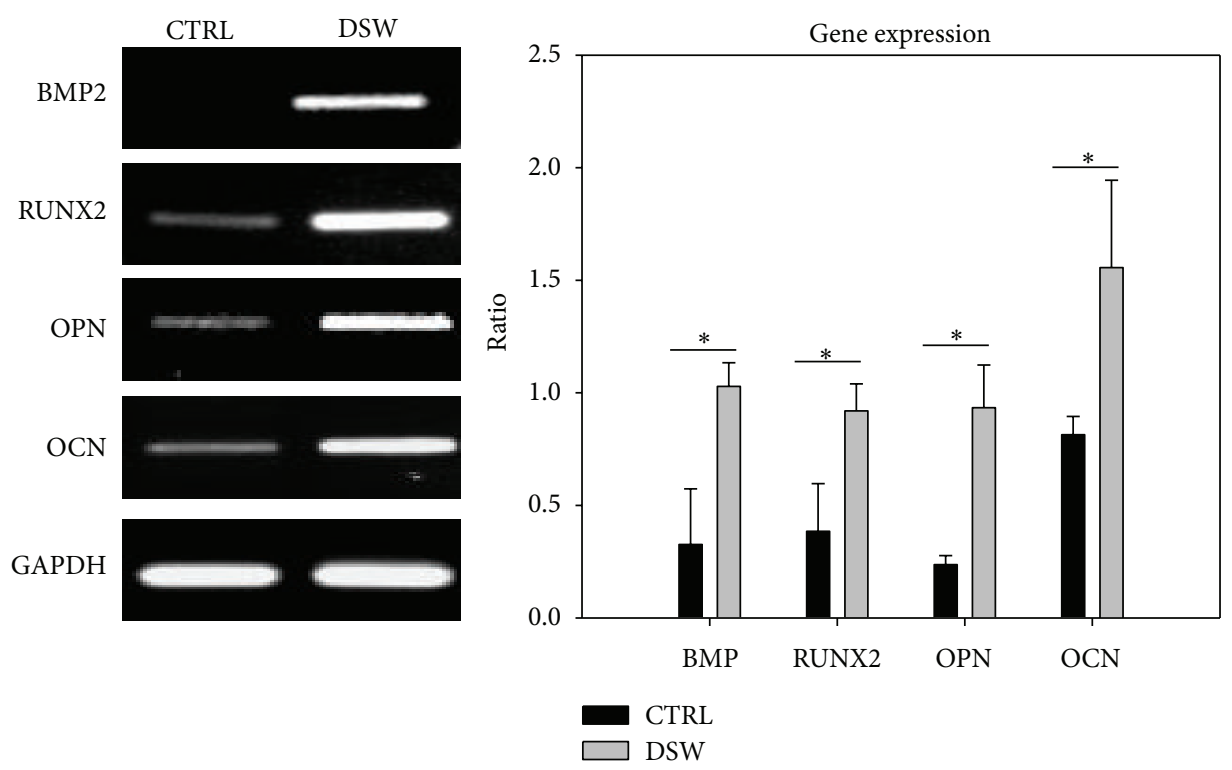

(a)
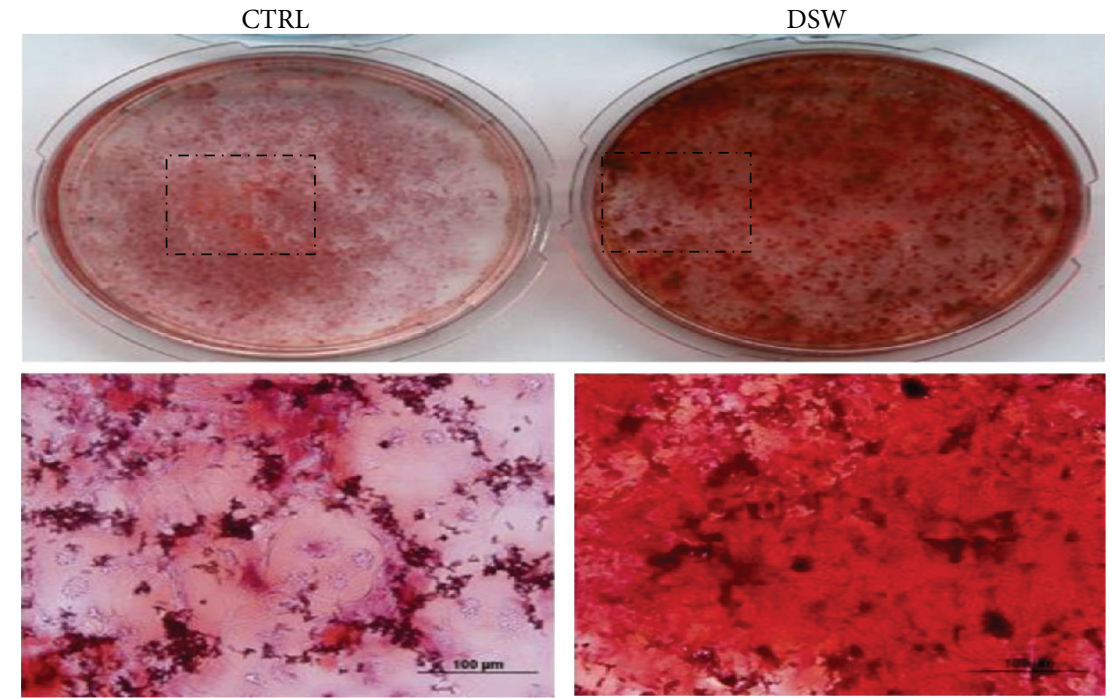

(b)

FIGURE 6: Comparative expression profile of osteogenic differentiation markers of BMSCs in osteoporotic mice. Effect of DSW on osteogenic mRNA expression in specific genes including bone morphogenetic protein 2 (BMP2), runt-related transcription factor 2 (RUNX2), Osteopontin (OPN) and Osteocalcin (OCN) of BMSCs was quantitatively measured ((a), right/left panel). The maturation of osteogenic differentiation was then examined by Alizarin Red S staining (b), and more calcium nodules were formed in DSW group. Representative results of 3 experiments are demonstrated; ${ }^{*} P<0.05$ versus CTRL group.

Interestingly, we initially used in vitro osteoblast cell culture to determine the effects of DSW on cell proliferation and colony formation; however, no effects were found (data not shown). Metabolism would be an important factor to be considered. Therefore, an alternative approach was designed and shown in general scheme of Figure 5(a). After administration of DSW, BMSCs in DSW-treated mice were then isolated and examined for cell proliferation and colony-forming ability. BMSCs obtained from DSWtreated mice showed markedly induction in osteogenesisrelated molecules including BMP2, RUNX2, OPN, and OCN
(Figure 6). BMP2 has been shown to regulate osterix via RUNX2 [37], an essential transcription factor for osteoblast differentiation [38]. During osteogenesis, OPN is an intermediate marker, while $\mathrm{OCN}$ is a late stage marker of osteoblasts [39]. DSW was found to strongly modulate the molecular determinants in bone microenvironment for osteogenesis. Meanwhile, the higher cell growth and colony formation were also detected in bone marrow cells isolated from DSWtreated mice (Figure 5). Taken together, DSW treatment enhanced bone formation in OVX-SAMP8 mice through metabolism. 


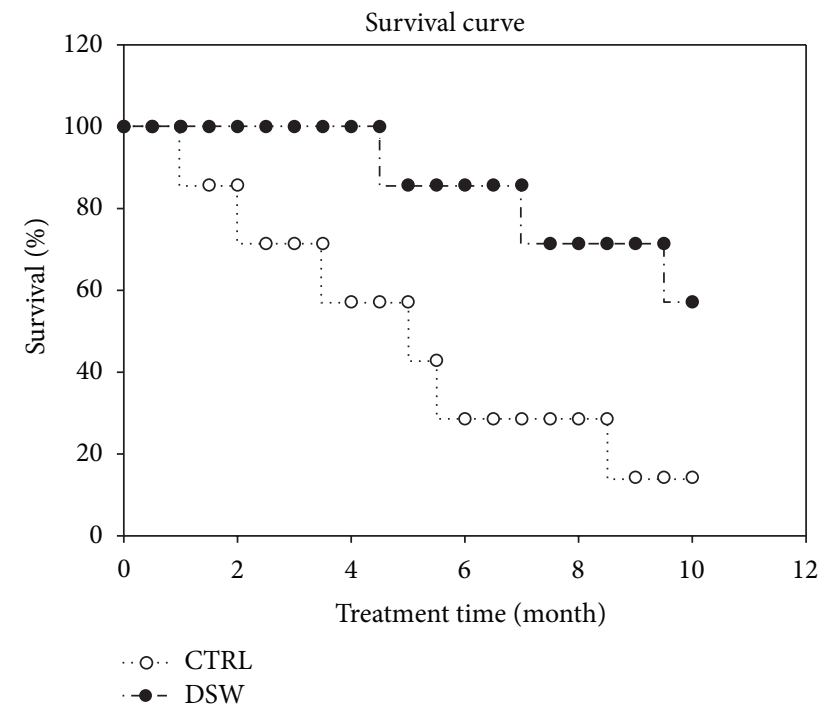

Figure 7: Survival of DSW-treated OVX-SAMP8 mice. The KaplanMeyer survival plots of mice from DSW (-•-) and vehicle groups (-o-) were shown.

Our data demonstrated that therapy with DSW appeared to prolong the life span of OVX-SAMP8 mice (Figure 7). Previously, we have shown that cell therapy with growth factors (PRP/NIH3T3-G) prolonged the life span of the osteoporotic mice through the bone mass recovery [16]. Epidemiologic studies indicated that the high mortality of hip fractures patients was 3-fold higher than those of general population. In contrast, the increased bone mass can also reduce the risk of bone fracture and subsequently increase the life expectancy in osteoporotic patients [40-42]. DSW treatment strongly indicated that not only bone mass was recovered but also osteogenesis was induced in osteoporotic mice and then potentially improving (regenerating) their structure and function in degenerative lesions, aging tissue, and organs. Furthermore, DSW treatment could be applied for rejuvenation therapy and bone regeneration for prolongation of life.

\section{Conclusion}

In this study, the potential effects of DSW on bone regeneration in osteoporosis recovery were investigated; we found that DSW promoted osteoblast viability and increased BMD scores, trabecular bone numbers, and ameliorated symptoms of osteoporosis. These findings suggest that DSW could be a useful treatment for preventing osteoporosis in the near future.

\section{Abbreviations}

DSW: Deep sea water

BMD: Bone mineral density

BMSCs: Bone marrow stromal cells.

\section{Conflict of Interests}

None of the authors have any conflict of interests with the mentioned trademarks, or companies.

\section{Authors' Contribution}

Hen-Yu Liu, Ming-che Liu, Rong Zeng, and Win-Ping Deng contributed equally to this work.

\section{Acknowledgments}

The authors thank the Taiwan Mouse Clinic which is funded by the National Research Program for Genomic Medicine (NRPGM) at the National Science Council (NSC) of Taiwan for technical support in bioimaging (micro-CT) and pathology (Histopathology) experiment and gratefully acknowledge Chi-Ming Lee, Wen-Tien Hsiao, and Milligrams Instruments Co., Ltd., for their excellent technical assistance in BMD measurement. Finally, the authors also thank the Taiwan Yes Deep Ocean Water Co., Ltd., for kindly providing the DSW (Deep Ocean Minerals, DOM) for this study. This research was supported by the following grants and agencies: National Science Council (101-2811-B-038-005), (NSC1012314-B-038-023) and (99-2628-B-038-010-MY3), the Department of Health (DOH) to Taipei Medical University-Center of Excellence for Cancer Research (TMU-CECR, DOH102TD-C-111-008), the Department of Health (DOH, DOH101TD-PB-111-NSC010), Teaching Resource Center of Excellence, Taipei Medical University (A0070-1200), and Stem Cell Research Center and Cancer Center, Taipei Medical University Hospital, Taipei, Taiwan.

\section{References}

[1] J. D. Adachi, G. Ioannidis, L. Pickard et al., "The association between osteoporotic fractures and health-related quality of life as measured by the Health Utilities Index in the Canadian Multicentre Osteoporosis Study (CaMos)," Osteoporosis International, vol. 14, no. 11, pp. 895-904, 2003.

[2] J. A. Robbins, M. L. Biggs, and J. Cauley, "Adjusted mortality after hip fracture: from the cardiovascular health study," Journal of the American Geriatrics Society, vol. 54, no. 12, pp. 1885-1891, 2006.

[3] R. S. Braithwaite, N. F. Col, and J. B. Wong, "Estimating hip fracture morbidity, mortality and costs," Journal of the American Geriatrics Society, vol. 51, no. 3, pp. 364-370, 2003.

[4] M. E. Wiktorowicz, R. Goeree, A. Papaioannou, J. D. Adachi, and E. Papadimitropoulos, "Economic implications of hip fracture: health service use, institutional care and cost in Canada," Osteoporosis International, vol. 12, no. 4, pp. 271-278, 2001.

[5] J. M. Lane, E. H. Riley, and P. Z. Wirganowicz, "Osteoporosis: Diagnosis and treatment," Journal of Bone and Joint Surgery A, vol. 78, no. 4, pp. 618-632, 1996.

[6] D. J. Hadjidakis and I. I. Androulakis, "Bone remodeling," Annals of the New York Academy of Sciences, vol. 1092, pp. 385396, 2006.

[7] C. C. Johnston Jr. and C. W. Slemenda, "Changes in skeletal tissue during the aging process," Nutrition Reviews, vol. 50, no. 12 , pp. 385-387, 1992.

[8] G. Duque, M. Macoritto, N. Dion, L. Ste-Marie, and R. Kremer, "1,25(OH)2D3 acts as a bone-forming agent in the hormoneindependent senescence-accelerated mouse (SAM-P/6)," American Journal of Physiology, vol. 288, no. 4, pp. E723-E730, 2005. 
[9] P. B. Saadeh, B. J. Mehrara, D. S. Steinbrech et al., "Transforming growth factor- $\beta 1$ modulates the expression of vascular endothelial growth factor by osteoblasts," American Journal of Physiology, vol. 277, no. 4, part 1, pp. C628-C637, 1999.

[10] G. Baczyk, T. Opala, P. Kleka, and M. Chuchracki, "Multifactorial analysis of risk factors for reduced bone mineral density among postmenopausal women," Archives of Medical Science, vol. 8, no. 2, pp. 332-341, 2012.

[11] R. P. Heaney, "Osteoporosis: management and treatment strategies for orthopaedic surgeons," Journal of Bone and Joint Surgery A, vol. 90, no. 11, pp. 2544-2545, 2008.

[12] H. S. Hwang, H. A. Kim, S. H. Lee, and J. W. Yun, "Anti-obesity and antidiabetic effects of deep sea water on ob/ob mice," Marine Biotechnology, vol. 11, no. 4, pp. 531-539, 2009.

[13] F. Maehira, Y. Iinuma, Y. Eguchi, I. Miyagi, and S. Teruya, "Effects of soluble silicon compound and deep-sea water on biochemical and mechanical properties of bone and the related gene expression in mice," Journal of Bone and Mineral Metabolism, vol. 26, no. 5, pp. 446-455, 2008.

[14] Z. Y. Fu, F. L. Yang, H. W. Hsu, and Y. F. Lu, "Drinking deep seawater decreases serum total and low-density lipoproteincholesterol in hypercholesterolemic subjects," Journal of Medicinal Food, vol. 15, no. 6, pp. 535-541, 2012.

[15] C. Lee, Y. Kung, J. Wang, T. Lung, and T. Pan, "Enhanced hypolipidemic effect and safety of red mold dioscorea cultured in deep ocean water," Journal of Agricultural and Food Chemistry, vol. 59, no. 15, pp. 8199-8207, 2011.

[16] W. Lo, J. Chiou, J. G. Gelovani et al., "Transplantation of embryonic fibroblasts treated with platelet-rich plasma induces osteogenesis in SAMP8 mice monitored by molecular imaging," Journal of Nuclear Medicine, vol. 50, no. 5, pp. 765-773, 2009.

[17] H. Liu, A. T. H. Wu, C. Tsai et al., "The balance between adipogenesis and osteogenesis in bone regeneration by platelet-rich plasma for age-related osteoporosis," Biomaterials, vol. 32, no. 28, pp. 6773-6780, 2011.

[18] H. Y. Liu, J. F. Chiou, A. T. Wu et al., “The effect of diminished osteogenic signals on reduced osteoporosis recovery in aged mice and the potential therapeutic use of adipose-derived stem cells," Biomaterials, vol. 33, no. 26, pp. 6105-6112, 2012.

[19] N. B. Watts, D. K. Jenkins, J. M. Visor, D. C. Casal, and P. Geusens, "Comparison of bone and total alkaline phosphatase and bone mineral density in postmenopausal osteoporotic women treated with alendronate," Osteoporosis International, vol. 12, no. 4, pp. 279-288, 2001.

[20] A. Rogers, R. A. Hannon, and R. Eastell, "Biochemical markers as predictors of rates of bone loss after menopause," Journal of Bone and Mineral Research, vol. 15, no. 7, pp. 1398-1404, 2000.

[21] P. D. Ross and W. Knowlton, "Rapid bone loss is associated with increased levels of biochemical markers," Journal of Bone and Mineral Research, vol. 13, no. 2, pp. 297-302, 1998.

[22] J. Y. Reginster, L. Strause, R. Deroisy, M. P. Lecart, P. Saltman, and P. Franchimont, "Preliminary report of decreased serum magnesium in postmenopausal osteoporosis," Magnesium, vol. 8, no. 2, pp. 106-109, 1989.

[23] R. K. Rude and M. Olerich, "Magnesium deficiency: possible role in osteoporosis associated with gluten-sensitive enteropathy," Osteoporosis International, vol. 6, no. 6, pp. 453-461, 1996.

[24] G. Candelas, J. A. Martinez-Lopez, M. P. Rosario, L. Carmona, and E. Loza, "Calcium supplementation and kidney stone risk in osteoporosis: a systematic literature review," Clinical and Experimental Rheumatology, vol. 30, no. 6, pp. 954-961, 2012.
[25] E. Abed, C. Martineau, and R. Moreau, "Role of melastatin transient receptor potential 7 channels in the osteoblastic differentiation of murine MC3T3 cells," Calcified Tissue International, vol. 88, no. 3, pp. 246-253, 2011.

[26] A. Creedon, A. Flynn, and K. Cashman, “The effect of moderately and severely restricted dietary magnesium intakes on bone composition and bone metabolism in the rat," British Journal of Nutrition, vol. 82, no. 1, pp. 63-71, 1999.

[27] T. O. Carpenter, S. J. Mackowiak, N. Troiano, and C. M. Gundberg, "Osteocalcin and its message: relationship to bone histology in magnesium-deprived rats," American Journal of Physiology, vol. 263, no. 1, part 1, pp. E107-E114, 1992.

[28] J. E. Sojka and C. M. Weaver, "Magnesium supplementation and osteoporosis," Nutrition Reviews, vol. 53, no. 3, pp. 71-74, 1995.

[29] A. Cagnacci, B. Bagni, A. Zini, M. Cannoletta, M. Generali, and A. Volpe, "Relation of folates, vitamin B12 and homocysteine to vertebral bone mineral density change in postmenopausal women. A five-year longitudinal evaluation," Bone, vol. 42, no. 2, pp. 314-320, 2008.

[30] S. Mora, L. Cafarelli, P. Erba et al., "Differential effect of age, gender and puberty on bone formation rate assessed by measurement of bone-specific alkaline phosphatase in healthy Italian children and adolescents," Journal of Bone and Mineral Metabolism, vol. 27, no. 6, pp. 721-726, 2009.

[31] P. Garnero and P. D. Delmas, "Assessment of the serum levels of bone alkaline phosphatase with a new immunoradiometric assay in patients with metabolic bone disease," Journal of Clinical Endocrinology and Metabolism, vol. 77, no. 4, pp. 10461053, 1993.

[32] R. Dresner-Pollak, M. Mayer, and D. Hochner-Celiniker, “The decrease in serum bone-specific alkaline phosphatase predicts bone mineral density response to hormone replacement therapy in early postmenopausal women," Calcified Tissue International, vol. 66, no. 2, pp. 104-107, 2000.

[33] E.-M. Lochmüller, D. Bürklein, V. Kuhn et al., "Mechanical strength of the thoracolumbar spine in the elderly: Prediction from in situ dual-energy X-ray absorptiometry, quantitative computed tomography (QCT), upper and lower limb peripheral QCT, and quantitative ultrasound," Bone, vol. 31, no. 1, pp. 7784, 2002.

[34] C. L. Benhamou, S. Poupon, E. Lespessailles et al., "Fractal analysis of radiographic trabecular bone texture and bone mineral density: two complementary parameters related to osteoporotic fractures," Journal of Bone and Mineral Research, vol. 16, no. 4, pp. 697-704, 2001.

[35] Y. Jiang, J. Zhao, P. Augat et al., “Trabecular bone mineral and calculated structure of human bone specimens scanned by peripheral quantitative computed tomography: relation to biomechanical properties," Journal of Bone and Mineral Research, vol. 13, no. 11, pp. 1783-1790, 1998.

[36] S. E. Tomten, J. A. Falch, K. I. Birkeland, P. Hemmersbach, and A. T. Høstmark, "Bone mineral density and menstrual irregularities. A comparative study on cortical and trabecular bone structures in runners with alleged normal eating behavior," International Journal of Sports Medicine, vol. 19, no. 2, pp. 9297, 1998.

[37] K. Nakashima, X. Zhou, G. Kunkel et al., “The novel zinc fingercontaining transcription factor Osterix is required for osteoblast differentiation and bone formation," Cell, vol. 108, no. 1, pp. 1729, 2002.

[38] T. Komori, H. Yagi, S. Nomura et al., "Targeted disruption of Cbfal results in a complete lack of bone formation owing to 
maturational arrest of osteoblasts," Cell, vol. 89, no. 5, pp. 755764, 1997.

[39] D. C. Wan, Y. Shi, R. P. Macamuli, N. Quarto, K. M. Lyons, and M. T. Longaker, "Osteogenic differentiation of mouse adiposederived adult stromal cells requires retinoic acid and bone morphogenetic protein receptor type IB signaling," Proceedings of the National Academy of Sciences of the United States of America, vol. 103, no. 33, pp. 12335-12340, 2006.

[40] J. Panula, H. Pihlajamäki, V. M. Mattila et al., "Mortality and cause of death in hip fracture patients aged 65 or older-a population-based study," BMC Musculoskeletal Disorders, vol. 12, article 105, 2011.

[41] A. Trombetti, F. Herrmann, P. Hoffmeyer, M. A. Schurch, J. P. Bonjour, and R. Rizzoli, "Survival and potential years of life lost after hip fracture in men and age-matched women," Osteoporosis International, vol. 13, no. 9, pp. 731-737, 2002.

[42] J. Empana, P. Dargent-Molina, and G. Bréart, "Effect of hip fracture on mortality in elderly Wwomen: The EPIDOS Prospective Study," Journal of the American Geriatrics Society, vol. 52, no. 5, pp. 685-690, 2004. 


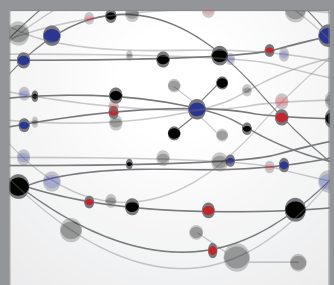

The Scientific World Journal
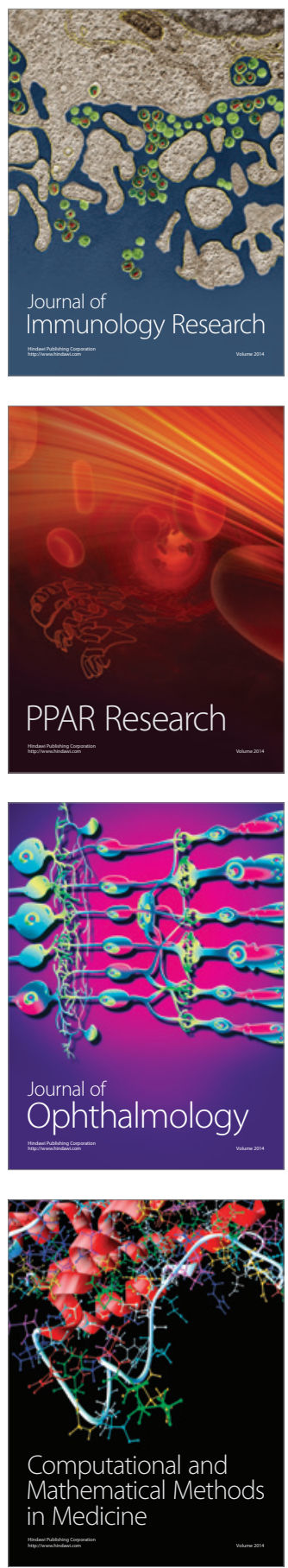

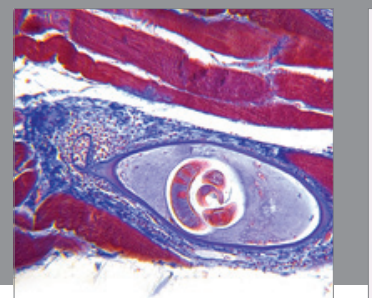

Gastroenterology

Research and Practice
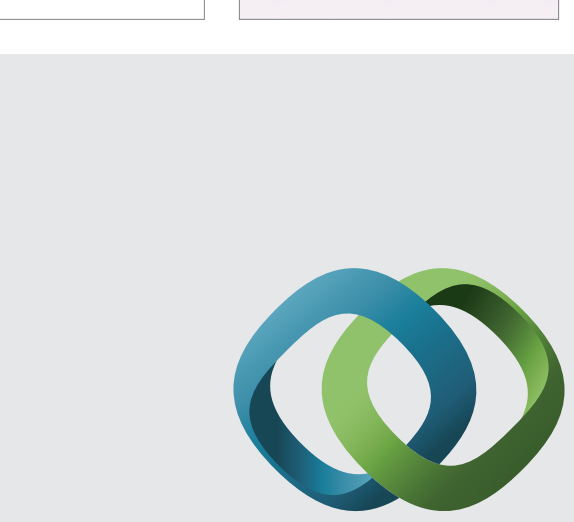

\section{Hindawi}

Submit your manuscripts at

http://www.hindawi.com
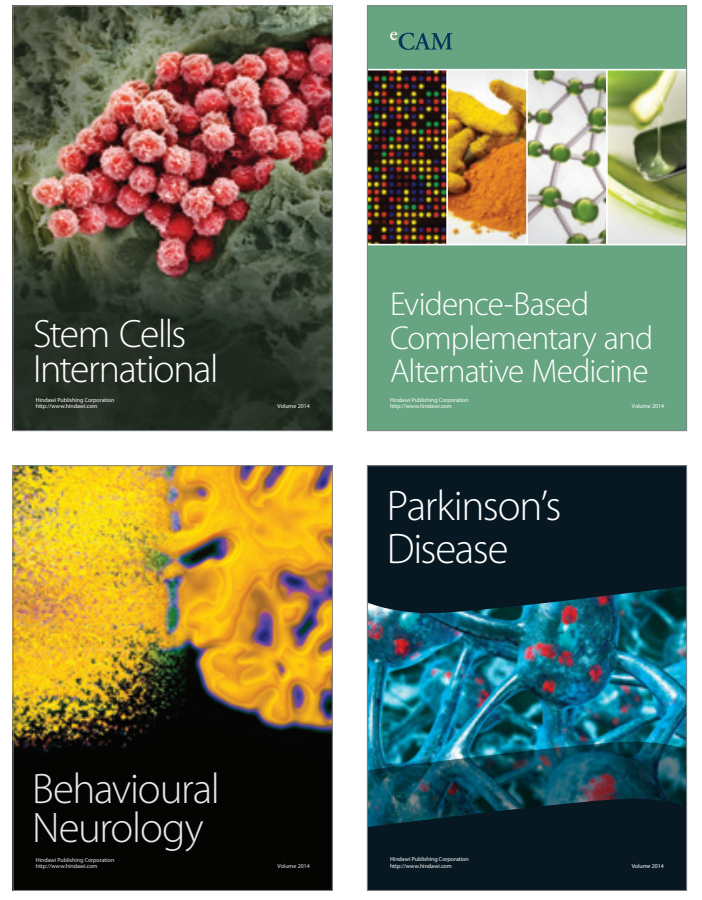
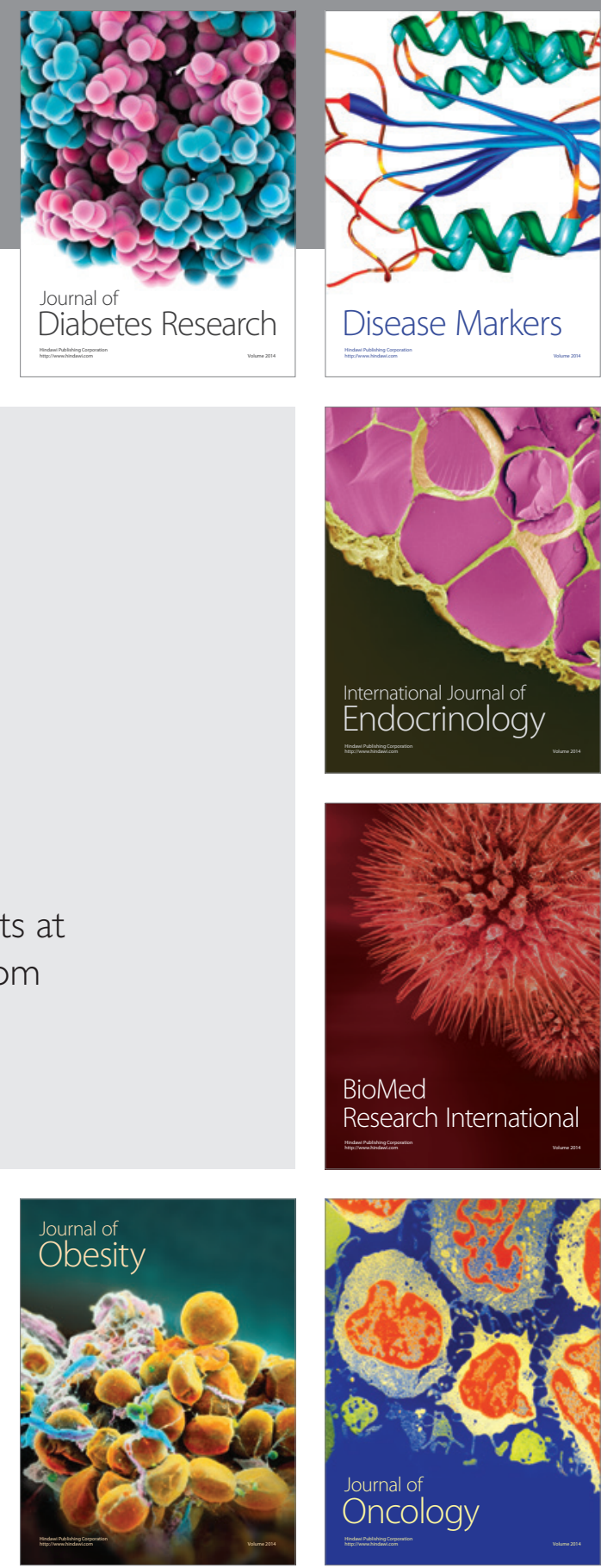

Disease Markers
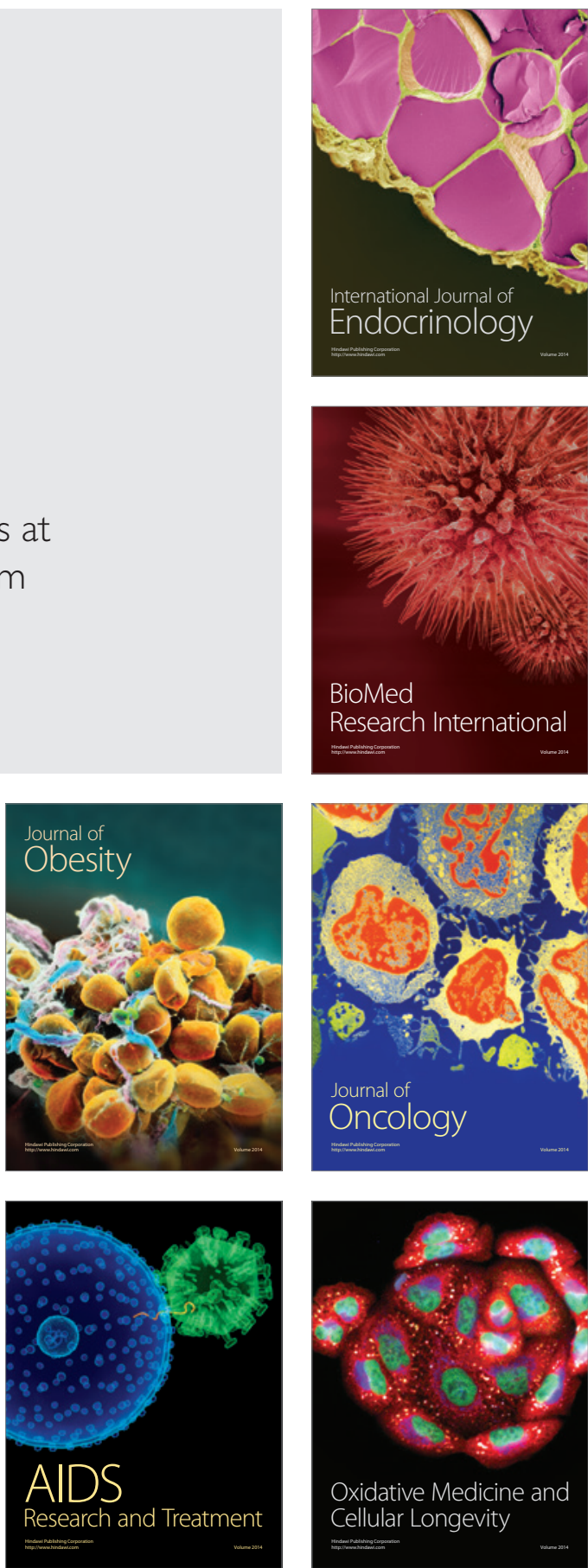